\title{
Metabolic profiling of cholesterol and sex steroid hormones to monitor urological diseases
}

\author{
Ju-Yeon Moon', Man Ho Choi'1 and Jayoung Kim²,3 \\ ${ }^{1}$ Molecular Recognition Research Center, Korea Institute of Science and Technology, Seoul, Korea \\ 2Departments of Surgery and Biomedical Sciences, Cedars-Sinai Medical Center, Los Angeles, California, USA \\ 3Department of Medicine, University of California, Los Angeles, California, USA
}

Correspondence should be addressed to $\mathrm{M} \mathrm{H}$ Choi or J Kim Email

mh_choi@kist.re.kr or Jayoung.Kim@cshs.org

\begin{abstract}
Cholesterol and sex steroid hormones including androgens and estrogens play a critical role in the development and progression of urological diseases such as prostate cancer. This disease remains the most commonly diagnosed malignant tumor in men and is the leading cause of death from different cancers. Attempts to understand the role of cholesterol and steroid metabolism in urological diseases have been ongoing for many years, but despite this, our mechanistic and translational understanding remains elusive. In order to further evaluate the problem, we have taken an interest in metabolomics; a discipline dedicated to the systematic study of biologically active metabolites in cells, tissues, hair and biofluids. Recently, we provided evidence that a quantitative measurement of cholesterol and sex steroid metabolites can be successfully achieved using hair of human and mouse models. The overall goal of this short review article is to introduce current metabolomic technologies for the quantitative biomarker assay development and also to provide new insight into understanding the underlying mechanisms that trigger the pathological condition. Furthermore, this review will place a particular emphasis on how to prepare biospecimens (e.g., hair fiber), quantify molecular profiles and assess their clinical significance in various urological diseases.
\end{abstract}

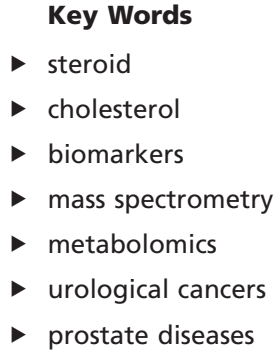

Endocrine-Related Cancer (2016) 23, R455-R467

\section{Introduction}

Urological health conditions have become increasingly prevalent in the world, affecting individuals spanning a multitude of ages. Prostate cancer (PC) is one such condition that has seen an exponential rise in the number of cases, with over 220,000 new cases having been recorded in 2015 alone. The effects of PC can even be seen outside of the USA, as it is the most common cancer among men in all developed countries. However, not all urological health problems are related to cancer, and the most common of these include the common occurrence of urinary tract infection, kidney stones, incontinence and benign prostatic hyperplasia (BPH). These diseases pose both a financial and physiological burden, indicating the need for further research in the prevention and study of these urological conditions. The use of biomarkers for early diagnosis in patients would be valuable in reducing the recurrence and progression of these urological health problems. As an example, there are clinical needs for biomarkers to identify PC patients who have aggressive disease and are more likely to experience disease progression, which could help increase the ability to manage patients with urological disease. 
Research has indicated that high levels of cholesterol and sex steroid hormones are risk factors of urological disease (Allott \& Hursting 2015). A correlation has been studied, relating a typical Western diet to an increase in the risk of urological disease (Ito 2014, YuPeng et al. 2015). Western diet normally features a high intake of red meat and dairy products, providing a high intake of cholesterol and calories to individuals consuming such foods (Ito 2014, YuPeng et al. 2015). These studies have also provided evidence that patients with a metabolic syndrome (e.g., obesity, impaired fasting glucose tolerance, high blood pressure, hypertension, dyslipidemia, type 2 diabetes and cardiovascular diseases) were more likely to have great prostate volume increase (Gacci et al. 2015), suggesting a high concentration of cholesterol within urological disease. Hypercholesterolemia, an obesity-associated co-morbidity, influences approximately $20 \%$ of the US population (Fryar et al. 2010). Furthermore, cholesterollowering drugs such as statins may reduce the risk of PC (Nielsen et al. 2012).

Sex steroids and their receptors play a crucial role in the determination of urological disease development. Androgen and its derivatives including dihydrotestosterone (DHT) are vital in not only male development but also the development of PC and $\mathrm{BPH}$. Following androgen binding, androgen receptors undergo a multi-step process involving dimerization, phosphorylation and translocation to the nucleus. Once localized, the receptor acts as a transcription factor and binds to androgen receptor elements (AREs) in order to begin assembling a transcription complex of co-activators and co-repressors (Dehm \& Tindall 2007). These complexes are key oncogenic risk factors associated with the increased risk of PC and $\mathrm{BPH}$.

In order to better understand the metabolism and internal mechanisms underlying urological diseases, several resources have been studied. Metabolomic fingerprints have been analyzed in addition to the use of non-invasive biomarkers such as urine or blood-based assays. Hair-based metabolomic profiles could be useful in confirming the correlation between cholesterol and sex steroid hormones with urological diseases. Using human and animal hair samples in order to study the metabolite process specific to urological disease, our research group established the novel mass spectrometry-based protocols for steroid metabolomics with the goal of monitoring hormone levels, which can be used for drug treatment of $\mathrm{PC}$ and $\mathrm{BPH}$ patients.

This short review article aims to provide support for the claim that a correlation exists between cholesterol and steroid sex hormones with urological diseases. By specifically examining PC and BHP, we discuss the significance of cholesterol and steroid sex hormones associated with these health conditions, while also introducing current technologies that can be used to measure the amount of cholesterol and sex steroid hormones in various sources throughout the body (tissues, urine, blood and hair). The final topic deals with the use of hair metabolomics to identify potential biomarkers for $\mathrm{PC}$ and $\mathrm{BPH}$.

\section{Metabolism of cholesterol and sex steroid hormones}

Cholesterol is a crucial component of mammalian cell membranes, as it serves diverse cellular functions including the modulation of membrane permeability and fluidity (Maxfield \& Tabas 2005). Cholesterol synthesis pathways are shown in Fig. 1. Cholesterol is also the precursor of all steroid hormones and bile acids and plays important roles in membrane trafficking, transmembrane signaling processes as well as cell proliferation (Goedeke \& Fernandez-Hernando 2012). Cholesterol is made from the conversion of citrate, derived from the tricarboxylic acid (TCA) cycle in the mitochondria. Here, acetyl coenzyme A (acetyl-CoA) is formed and followed by the mevalonate pathway. This combination of reactions is primarily regulated by a rate-limiting step catalyzed by 3-hydroxy3-methylglutaryl-coenzyme A (HMG-CoA) reductase, an integral membrane protein of the smooth endoplasmic reticulum, which converts HMG-CoA to a six-carbon intermediate mevalonate. This intermediate is then metabolized via a series of isoprenoid intermediates to squalene (the polymerization of six five-carbon isoprene units to form the 30-carbon linear structure of squalene). The cyclization of squalene reacted by squalene cyclase and one molecule of $\mathrm{O}_{2}$ forms the four fused rings of the steroid nucleus, which results in the synthesis of lanosterol as a cholesterol precursor.

Cholesterol in tissues and blood is metabolized as follows. First, it can be fatty acylated to form cholesteryl esters (CEs) through sterol $O$-acyltransferase (also called acyl-CoA cholesterol acyltransferase or simple ACAT) or lecithin-cholesterol acyltransferase (LCAT, also called phosphatidylcholine-sterol $\mathrm{O}$-acyltransferase). The CEs then serve as a major form of transporter as plasma lipoproteins, or as storage units in the form of lipid droplets (Kraemer 2007). Secondly, cholesterol can be oxidized to form oxygenated derivatives of cholesterol, termed oxysterols, by enzymatic (hydroxylase, cytochrome P450 (CYP) families) or non-enzymatic hydroxylations at the C-4, C-7, C-19, C-20, C-24, C-25 and C-27 positions

Published by Bioscientifica Ltd 


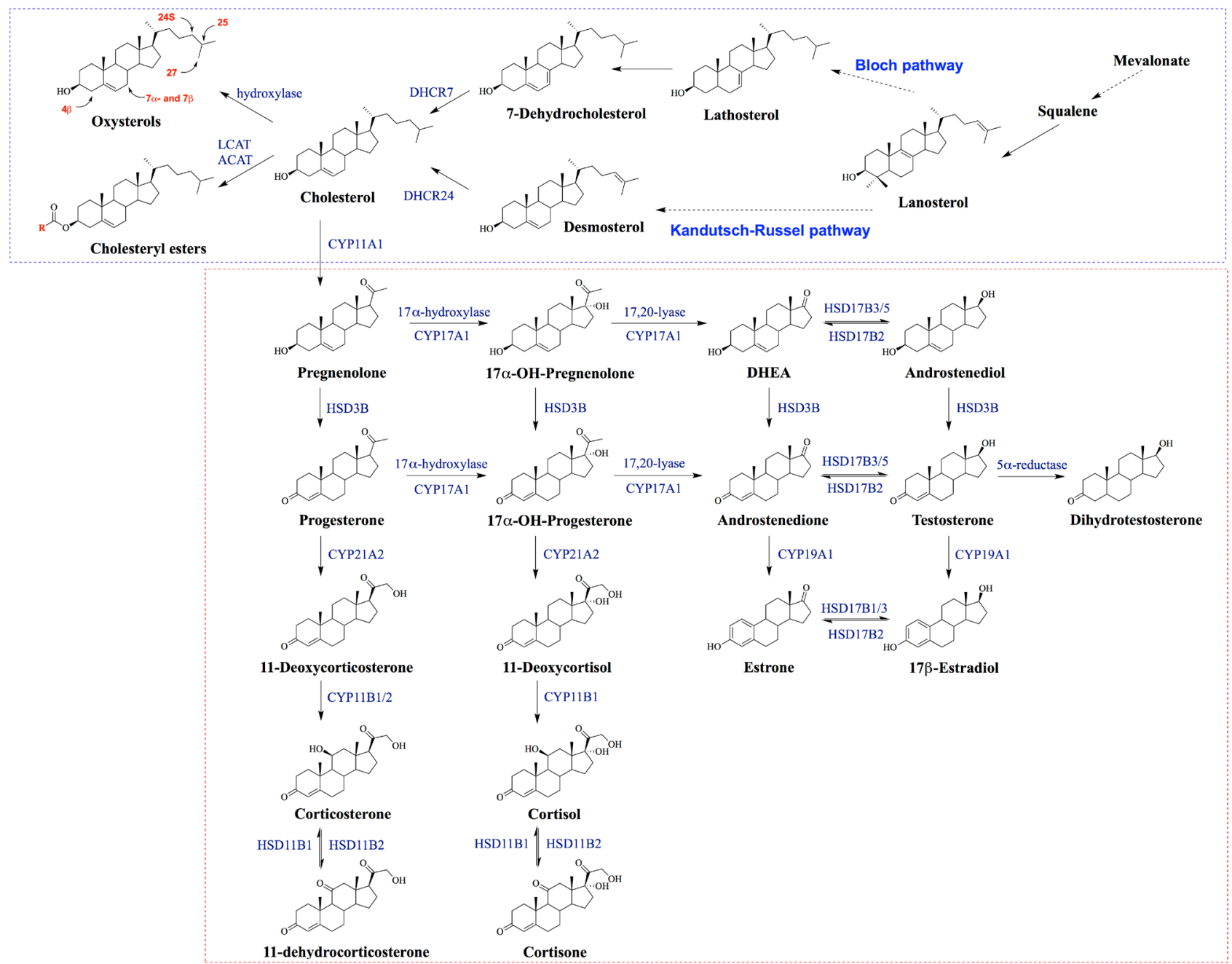

Figure 1

Overview of cholesterol and steroid hormone pathways.

(Pikuleva 2006, Son etal.2014, Seo \& Choi 2015). Oxysterols serve as regulators of cholesterol homeostasis, allowing cells to manage large cholesterol loads rapidly and avoid triggering cytotoxic events (Bjorkhem 2002, Bielska et al. 2012). For example, cholesterol activates $7 \alpha$-hydroxylase (CYP7A1), which produces $7 \alpha$-hydroxycholesterol as the major pathway for elimination of cholesterol from the body (Bjorkhem 2002). In addition, the most important oxysterols (as transport forms of cholesterol) are side chain-oxidized oxysterols at the C-24 or 27 position by CYP46 and CYP27, respectively, which flow continuously from peripheral tissues to the liver and become further oxidized into bile acids or other water-soluble metabolites (Nielsen et al. 2012). 4ß-hydroxycholesterol catalyzed by CYP 3A4 may indicate slow elimination when its levels are high in the blood (Bodin et al. 2002). In addition, the 25-hydroxycholesterol that is produced and secreted by macrophages can regulate interleukin- $1 \beta$, a potent cytokine, facilitating cross talk between cholesterol metabolism and the immune system (Simon 2014).

Cholesterol is also metabolized to steroid hormones, which regulate physiological and pharmacological processes in the body (Falkenstein et al. 2000). Steroidogenic enzymes are responsible for the biosynthesis of cholesterol from various steroid hormones including corticoids, progestins, androgens and estrogens. These are generally synthesized in the adrenal cortex, gonads (testes and ovaries), brain, placenta and adipose tissue (Falkenstein et al. 2000, Payne \& Hales 2004). In biosynthetic pathways of steroid hormones, two major types of enzymes are involved: cytochrome P450 enzymes (CYPs) and hydroxysteroid dehydrogenases (HSDs). 
Initially, steroid hormones start with the conversion of cholesterol to pregnenolone by rate-limiting enzyme CYP11A (cholesterol side-chain cleavage), which is bound to the inner membrane of the mitochondrion in all steroidogenic tissues. This acute regulation is mediated by the steroidogenic acute regulatory protein (StAR) on the outer membrane, which facilitates the rapid influx of cholesterol into mitochondria (Payne \& Hales 2004, Miller 2008).

\section{Cholesterol and sex steroid hormones in prostate health}

Cholesterol, a critical component of the cellular plasma membrane, contributes to the maintenance of plasma membrane fluidity. Also, cholesterol is an important component of lipid raft micro-domains on plasma membrane and regulates intracellular signaling processes (Krycer \& Brown 2013). Cholesterol is also the precursor for endogenous sex steroid biosynthesis, suggesting that elevated serum cholesterol levels might be somehow linked to the increased risk of prostate cancer (Fagherazzi et al. 2010). Steroid biosynthesis may be an important mechanism linking cholesterol and prostate cancer and $\mathrm{BPH}$.

StAR and CYP11A are involved in converting cholesterol into pregnenolone and progesterone, which are sequentially converted to DHEA and androstenedione by CYP17A. DHEA is then converted to form testosterone and then DHT via HSD3B, HSD17B3 (or AKR1C3) and SRD5A. The $5 \alpha$-androstanedione pathway leads to produce DHEA, androstenedione and then testosterone. There are multiple enzymes, which actively play roles in cholesterol and sex steroid hormone synthesis. AKR1C1 converts DHT to $5 \alpha$-androstane-3,17-diol ( $3 \alpha$-androstanediol or $3 \alpha$-diol) and AKR1C2 converts DHT to $5 \alpha$-androstane3,17-diol (33-diol). UGT2B15 and UTG2B17 irreversibly inhibit androgen signaling by glucuronidation, which is the known rate-limiting step of androgen signaling.

Prostate epithelial cells have higher cholesterol content, compared with other organs, and cholesterol levels increase during progression of normal healthy prostate into PC or BPH (Krycer \& Brown 2013), suggesting that cholesterol accumulation may benefit prostate cancer or $\mathrm{BPH}$ progression. Accumulating evidence demonstrates that elevated cholesterol is a risk factor of more aggressive PC - in terms of recurrence or mortality (Platz et al. 2008, 2009, Farwell et al. 2011, Mondul et al. 2011, Shafique et al. 2012). Our previous studies also support the hypothesis that cholesterol promotes PC growth in vitro and in vivo
(Zhuang et al. 2002). Cholesterol-lowering drugs (e.g., statins, zetia or combination of both) also lowered serum as well as intratumoral androgen levels, leading to the arrest of tumor growth (Mostaghel et al. 2012). Statins have been used for patients with cardiovascular diseases (Ridker \& Cook 2013). There are a series of epidemiological studies suggesting that statins could reduce cancer risk (Farwell et al. 2008), chronic inflammation and angiogenesis (Demierre et al. 2005, Pelton et al. 2012). However, several meta-analyses have also reported a null association between statin use and risk of prostate cancer recurrence (Mass et al. 2012, Park et al. 2013, Scosyrev et al. 2013), suggesting that they remain contradictory in the field.

\section{Analytical techniques for sex steroid metabolome}

\section{Tissue- and biofluid-based metabolite profiling}

As the most common specimens used in biomarker discovery, tissues and biological fluids have been used for metabolite profiling. Both formalin-fixed, paraffinembedded (FFPE) and fresh-frozen tissue specimens can be used for the tissue-based metabolomic studies. Metabolite extraction from FFPE tissues includes de-paraffinization steps with xylene, homogenization in $\mathrm{MeOH}: \mathrm{H}_{2} \mathrm{O}$ solution $(1: 1 \mathrm{v} / \mathrm{v})$, vortexing and sonication.

Biofluids such as urine and serum have a great advantage of being the easiest samples to work with, urine being the most common and accessible samples for metabolomic analyses. Metabolome in urine can be greatly influenced by age, occupation, environmental factors, different diets, hormones and lifestyle such as exercise, and urine specimens should be immediately stored within a few hours after sample collection at $-80^{\circ} \mathrm{C}$ until further analysis.

In order to identify the steroid signatures and to suggest steroid metabolism-associated enzyme activities through profiling of tissues or biofluid-derived metabolites, we can use quantitative mass spectrometry combined with gas or liquid chromatographic separation techniques (GC-MS or LC-MS) for steroid profiling. Our previous studies to develop the quantitative steroid signatures using GC-MS (Ha et al. 2009, Moon et al. 2009) demonstrated that we could measure concentrations of over 65 endogenous steroids and cholesterols in plasma or urine samples at a time. In addition, LC-MS-based steroid profiling enables to quantify 21 endogenous corticoids including urinary glucocorticoids and mineralocorticoids (Cho et al. 2009). Both GC-MS and LC-MS urinary steroid signatures were

Published by Bioscientifica Ltd 


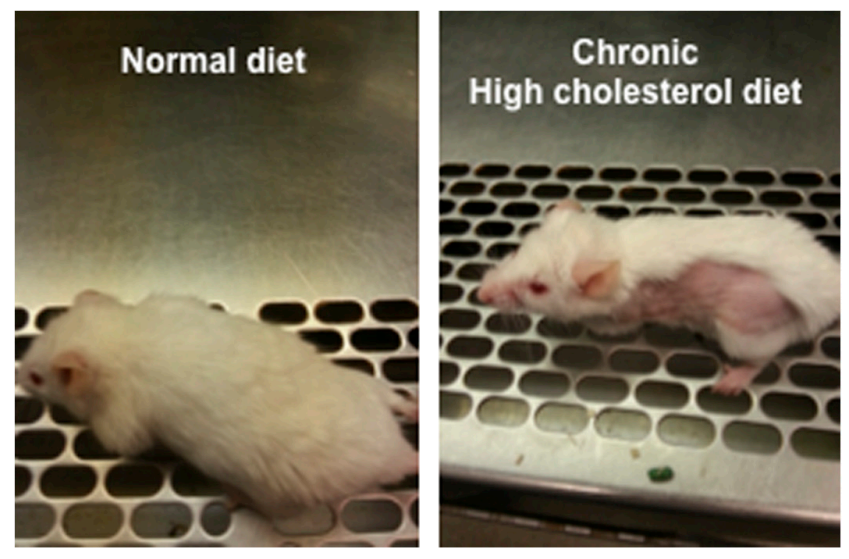

Figure 2

Our metabolomic profile showing the distinct patterns between prostate cancer and healthy controls.

applied into the samples obtained from patients with PC or BPH from age- and gender-matched healthy subjects.

As a good example, our GC-MS analysis data showed that urinary cholesterol levels in $\mathrm{BPH}$ patients were significantly increased in those with healthy controls $(P=0.015)$ (Fig. 2A). First morning urine samples obtained from $59 \mathrm{BPH}$ patients (age: $65.3 \pm 8.2$ years) and 41 healthy male subjects (age: $56.7 \pm 7.1$ years) were used for this analysis. We screened various cholesterol and sex hormones and found that cholesterol level could segregate BPH patients from healthy controls (AUC, 0.66) (Fig. 2B).

\section{Hair metabolomics for hair-based metabolite profile}

Although urine and blood are widely used to measure sex steroid hormones in many clinical and toxicological studies (Wudy et al. 2000, Choi et al. 2011, Choi \& Chung 2015, Son et al. 2015), their concentrations fluctuate on a daily basis. Additionally, careful handling of biological fluids is required for sample collection, handling, processing, storage and transport to the laboratory (Tworoger \& Hankinson 2006) under controlled circumstances. In contrast, hair grows about $1 \mathrm{~cm}$ per month (Wennig 2000). Thus, it can offer the possibility of reflecting and revealing historical information of exposure to drug abuse, environmental toxins and endogenous or exogenous hormones over several months (Villain et al. 2004). Moreover, hair sampling is non-invasive and the storage and processing of it is much simpler than plasma or serum (Sulek et al. 2014). Therefore, hair analysis has been used in chemical toxicology, forensic science, doping control and clinical applications (Cho et al. 2010, Pichini et al. 2012, Choi et al. 2013, Gray et al. 2013,
Pereg et al. 2013, Chan et al. 2014, Veldhorst et al. 2014, Son et al. 2016).

Sample preparation: extraction from hair fiber Hair analysis in steroid research is mainly coupled with solubilization or digestion of the hair matrix after cutting (Choi et al. 2001a, 2013, Cho et al. 2010). In general, androgens and sterols are extracted from the hair matrix by alkaline hydrolysis involving the complete digestion of hair (Choi \& Chung 1999, Choi et al. 2000, Ryu et al. 2006), whereas corticoids are unstable under these conditions. Hence, ultrasonication with an organic solvent was also tested for steroid profiling including androgens, sterols, corticoids and progestins, which enables the profiling of hair steroids (Jung et al. 2011). A mixed solvent of methanol and dichloromethane is an effective solvent for lipid extraction from biological samples (Folch et al. 1957). However, absolute methanol was chosen as the extraction solvent to decrease sample complexity and simplify the sample purification steps. The hair strands were washed with isopropyl alcohol to prevent contamination and were then obtained simply by cutting the specific lengths from the proximal part of the vertex scalp (Jung et al. 2011). Thirty milligrams of chopped hair were incubated with $0.5 \mathrm{~mL}$ methanol in an ultrasonic bath for $1 \mathrm{~h}$ at $50^{\circ} \mathrm{C}$. After cooling to room temperature, a methanolic solution was diluted with $5.5 \mathrm{~mL}$ sodium acetate buffer ( $\mathrm{pH}$ 5.2) to less than $8 \%$ methanol. The samples were loaded directly onto the Oasis HLB ${ }^{\mathrm{TM}}$ (divinylbenzene and $\mathrm{N}$-vinylpyrrolidone) solid-phase extraction (SPE) cartridge, which is preferable for the sample purification of steroidal compounds (Moon et al. 2009, Choi \& Chung 2015). The SPE procedure removed more effective interference from the hair matrix and gave a lower matrix background than liquid-liquid extraction (LLE) (Mondul et al. 2011). However, these extraction processes require a relatively large amount of hair matrix and extensive, timeconsuming pretreatment procedures.

Recently, the pulverization method has been used to highly disintegrate hair components and has allowed for efficient extraction (Miyaguchi et al. 2007, Kim et al. 2011, Son et al. 2016). Compared with our previous techniques (Ryu et al. 2006, Jung et al. 2011), this method enables increased extractable surface area of the hair matrix through the destruction of the cuticle layer and thereby the permeation of an extraction solvent into the hair. The pulverization of hair using a ball mill such as zirconia beads was achieved for improved extraction yields of steroids and sterols and therefore can reduce sample preparation

Published by Bioscientifica Ltd. 
times as well as sample amounts significantly. Therefore, hair steroid analysis has been successfully applied in clinical applications using sampling of 100-150 strands of hair and extraction from a minimum of $10 \mathrm{mg}$ (Choi et al. 2013). Hair sterols were measured in only two strands of $3 \mathrm{~cm}$ hair segments, corresponding roughly to a period of recent 3 months.

The sample preparation technique is also required for the removal of endogenous matrix components from lipid-rich samples. In particular, phospholipids are extremely abundant in hair as well as blood (Singh \& Gershbein 1967). The use of hybrid precipitation/SPE plates for selective removal of phospholipids and precipitated proteins has been increasing over the past few years (Bylda et al. 2014). The hybrid SPE-precipitation cartridge (H-PPT) applies to reduce the phospholipidbased matrix effect, which is a superior purification method for sterol analysis (Pucci et al. 2009, Son et al. 2014) relative to membrane filtration (Miyaguchi et al. 2007). The H-PPT specifically retains phospholipids by Lewis acid-base interactions between the zirconia-coated silica particles bonded to the stationary phase and the phosphate group of the phospholipids, which provides simple yet rapid selective removal of interference (Bylda et al. 2014). When the extraction recoveries of the sterols were compared at different pulverization times $(1,2,5,10,15$ and $20 \mathrm{~min})$ and different frequencies $(10,15,20,25$ and $30 \mathrm{~Hz}), 10 \mathrm{~min}$ at $25 \mathrm{~Hz}$ was chosen as the optimized extraction method (Son et al. 2016). To facilitate sterol extraction, two strands of $3 \mathrm{~cm}$-long hair samples were pulverized in $0.5 \mathrm{~mL}$ methanol using a TissueLyser for $10 \mathrm{~min}$ at $25 \mathrm{~Hz}$ in a $2 \mathrm{~mL}$ Safe-Lock tube containing three zirconia beads (3.0 mm I.D.). Bead-assisted liquid-liquid extraction via the addition of methanol and then centrifugation can be achieved simultaneously with pulverization, extraction and protein precipitation (Son et al. 2016). Samples were then loaded into H-PPT cartridges and eluted three times with $0.5 \mathrm{~mL}$ methanol. The matrix background such as proteins and phospholipids was easily removed and finally hair sterols were collected.

Sample pretreatment: chemical derivatization In GC separation, derivatization of steroid molecules is a prerequisite step to generate compounds with better volatility, thermal stability and thereby improved chromatographic properties (Marcos \& Pozo 2015). The common reactions used in GC analysis are silylation, acylation and alkylation (Choi \& Chung 2015), depending on the individual properties of the steroid and the detection system. Silylation is the most widely used derivatization reaction in steroid analysis, and trimethylsilyl (TMS) derivatization is extensively used for most functional groups on steroid backbone, including aliphatic and phenolic alcohols, and carbonyl and amine groups. The purpose of this is to increase volatility as well as MS characteristics for GC-MS (Choi et al. 2002, Moon et al. 2009, Marcos \& Pozo 2015). The most common reagents are $\mathrm{N}, \mathrm{O}$-bis (trimethylsilyl)-trifluoroacetamide (BSTFA) and the more volatile $\mathrm{N}$-methyl- $\mathrm{N}$-trimethylsily ltrifluoroacetamide (MSTFA) as a powerful trimethylsilyl (TMS) donor in the derivatization procedure (Shareef et al. 2006, Marcos \& Pozo 2015). One of the most reported derivatization techniques in steroid profiling is the application of a mixture of MSTFA/ammonium iodide $\left(\mathrm{NH}_{4} \mathrm{I}\right) /$ dithioerythritol (DTE) in a ratio of 500:4:2 (v/w/w) (Moon et al. 2009, 2010, Jung et al. 2011, Son et al. 2015). Most steroids were monitored using their molecular ions as base peaks.

For the profiling of 18 sterols, including cholesterol, six CEs, three cholesterol precursors and eight OHCs Cholesterol and cholesterol precursors have a hydroxyl group at the C-3 position, and OHCs have two polar functional groups: one is a hydroxyl group at the C-3 position and the other is a hydroxyl or ketone group at the C-4, C-7, C-19, C-20, C-24, C-25 or C-27 position. In TMS derivatization, both hydroxyl and carbonyl ketone groups were derivatized with TMS, whereas CEs were unaffected by TMS agents because they do not have polar groups in their chemical structures. The characteristic ions of cholesterol were observed at $m / z 458[\mathrm{M}]^{+}, m / z 443\left[\mathrm{M}-15 ; \mathrm{M}-\mathrm{CH}_{3}\right]^{+}, m / z$ 368 [M-90; M-OTMS] + , m/z 353 [M-90-15; M-OTMS$\left.\mathrm{CH}_{3}\right]^{+}, \quad m / z \quad 329 \quad\left[\mathrm{M}-129 ; \quad \mathrm{M}-\mathrm{TMS}^{-\mathrm{O}^{+}}=\mathrm{CHCH}=\mathrm{CH}_{2}\right]^{+}$ and $m / z \quad 129\left[\mathrm{TMS}^{-\mathrm{O}^{+}}=\mathrm{CHCH}=\mathrm{CH}_{2}\right]^{+}$, which are in accordance with a general mass spectral interpretation. Among these fragments, the $m / z 368$ ion was chosen as the quantitative ion. All CEs generated a base peak at $m / z 368$ by cleavage of the ester bond, regardless of the fatty acid moiety (Jung et al. 2009). The quantitative ion of desmosterol was selected to be the $\mathrm{m} / \mathrm{z} 343$ ion that was formed by the loss of the side chain and two nuclear hydrogens. The quantitative ions of lathosterol and lanosterol were selected to be $m / z 458[\mathrm{M}]^{+}$and $m / z$ 393 [M-90-15]+, respectively. In addition, OHCs showed different fragmentation patterns depending on the $-\mathrm{OH}$ positions (Moon et al. 2014). These results may provide useful information about the chemical structures of cholesterol and its metabolites.

Published by Bioscientifica Ltd. 
For chemical transformation of multi-functional steroids Mixed derivatization is performed to improve physical and chemical properties and mass spectral characteristics. Sensitive and selective quantification of eight steroids related to androgen biosynthesis in human hair was achieved by a combination of TMS and pentafluorophenyldimethylsilylation (flophemesylTMS) (Choi \& Chung 1999). The spectra of flophemesyl derivatives generally display intense molecular ions under electron impact ionization, resulting in enhanced chromatographic selectivity and mass spectral information with sensitive detection (Choi et al. 2001a, Choi \& Chung 2015). Recently, the enhanced GC-MS analytical selectivity and sensitivity were allowed for quantitative analysis of estrogen metabolites in urine samples obtained from the postmenopausal female patients with osteoporosis (Moon et al. 2011b). It was successfully achieved by two-phase extractive ethoxycarbonylation (EOC) and subsequent pentafluoropropionyl (PFP) derivatization. In case of estrogen profiling, the ultrasensitive LC-MS analytical method has been conducted with a novel chemical derivatization procedure, which formed analytes as pre-ionized $\mathrm{N}$-methyl pyridinium-3sulfonyl (NMPS) derivatives (Wang et al. 2015).

Analytical instrumentation Although radioimmunoassay (RIA) or enzyme immunoassays (EIA) are widely used to evaluate the quantification of steroid molecules (Thomson et al. 2009, Musshoff et al. 2012, Chan et al. 2014), the specificity of these methods is relatively low, which may result in an overestimation of the actual steroid content in samples. Furthermore, only single enzymes are estimated at a single time (Spiehler 2000, Hsing et al. 2007, Wood et al. 2008), making the method even more inaccurate. In contrast, mass spectrometrybased quantification has better reproducibility and generates multi-targeted profiling analysis (Cho et al. 2009, Ha et al. 2009, Jung et al. 2009, 2011, Moon et al. 2009, Son et al. 2015).

Several mass spectrometric methods for the measurement of steroids and sterols from various biological matrices have been proposed, coupled to GC (Ahmida et al. 2006, Ryu et al. 2006, Moon et al. 2009, 2011b, 2014, Choi et al. 2011, 2013, Son et al. 2014, 2015) or LC (Lembcke et al. 2005, Griffiths et al. 2008, DeBarber et al. 2008, Honda et al. 2009, Karu et al. 2011). The LC-MS methods based on electrospray and atmospheric pressure chemical ionization techniques have been conducted with a good sensitivity and chromatographic resolution of estrogens (Falk et al. 2008, Penning et al. 2010,
Wang et al. 2015), sterols and oxysterols (Burkard et al. 2004, Karuna et al. 2009, McDonald et al. 2012). However, the method often requires sample derivatization with dansyl chloride (Falk et al. 2008), pentafluorobenzyl chloride (Penning et al. 2010), Girard P hydrazine (Griffiths et al. 2006), picolinyl esterification (Yamashita et al. 2007, Honda et al. 2009) and NMPS (Wang et al. 2015) to improve ionization efficiencies and detection sensitivity. These methods enable to quantify the analytes in the low $\mathrm{pg} / \mathrm{mL}$ ranges but are time-consuming because they require derivatization (Yamashita et al. 2007, Honda et al. 2009) and a long analytical run (Xu et al. 2007). Girard $\mathrm{P}$ derivatization can be seen in more detailed structure information due to $\mathrm{MS}^{3}$ (MS/MS/MS) applicability, but it appeared more laborious than GC-MS-based methods (Griffiths et al. 2006).

In particular, GC-MS with electron impact ionization is used widely for the measurement of steroid hormones with good analytical efficiencies as well as structural information. Initially, eight steroids related to androgen biosynthesis and two main estrogens (estrone and $17 \beta$-estradiol) were determined in hair (Choi et al. 2000, Choi \& Chung 2015). In 2011, the simultaneous quantification of hair steroids, including androgens, progestins, corticoids and sterols by GC-MS method in selected ion monitoring (SIM) mode, was successfully validated to evaluate the concentrations of individual steroids as well as the activities of the enzymes responsible for steroidogenesis in hair follicles and sebaceous glands (Jung et al. 2011). This can synthesize many steroids from cholesterol or locally convert circulating steroids with a range of metabolic enzymes (Chen et al. 2002, Ohnemus et al. 2006). For hair steroid profiling, 62 steroids were analyzed on an Ultra- 1 capillary column $(25 \mathrm{~m} \times 0.2 \mathrm{~mm}$ i.d., $0.33 \mu \mathrm{m}$ film thickness), and only 20 hair steroids, including eight androgens, three progestins, five sterols and four corticoids, were detectable (Jung et al. 2011).

Compared with the conventional GC-MS techniques using a fused silica capillary column (Ahmida et al. 2006), high-temperature gas chromatography-mass spectrometry (HTGC-MS) with a thermally stable stainless steel capillary column is described as an alternative technique for the analysis of lipophilic compounds (Son et al. 2014). In previous studies, it successfully achieved good chromatographic properties for the analysis of lipid molecules including cholesterols (Jung et al. 2009, 2010), as well as estrogens with two-phase extractive EOC and subsequent PFP derivatization (Moon et al. 2011a,b). Results showed that lower bleeding achieved results in better detectability with a short analytical run compared with

Published by Bioscientifica Ltd. 
A

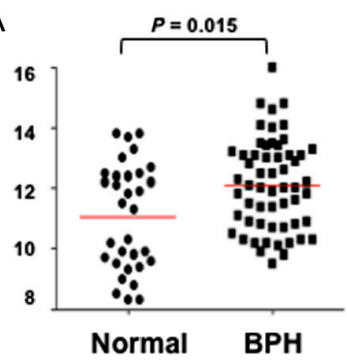

B

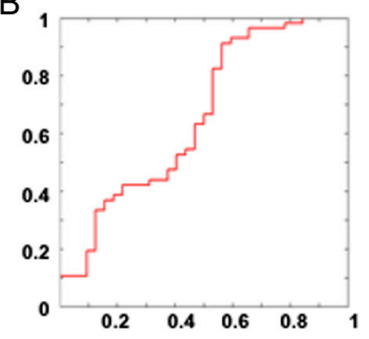

\begin{tabular}{|l|l|}
\hline Sterols & Cholesterol \\
\hline AUC & 0.66 \\
\hline $95 \% \mathrm{Cl}$ & 0.54 \\
& 0.77 \\
\hline P value & $\mathbf{0 . 0 0 4}$ \\
\hline
\end{tabular}

Figure 3

High cholesterol, high sex steroids and hair loss were observed in mice with chronic high-cholesterol diet. Line within the value represents the median. a fused silica GC column. The present HTGC-MS-based quantitative cholesterol signatures of 18 sterols including cholesterol, six cholesteryl esters (CEs), three cholesterol precursors and eight oxysterols have been conducted with H-PPT purification and GC separation through a HTGC column separation. All analytes were successfully separated and detected without any interference within a 27-min chromatographic run. The oven temperature was held initially at $260^{\circ} \mathrm{C}$ for $3 \mathrm{~min}$, ramped to $320^{\circ} \mathrm{C}$ at $10^{\circ} \mathrm{C} / \mathrm{min}$, increased to $330^{\circ} \mathrm{C}$ at $2^{\circ} \mathrm{C} / \mathrm{min}$ (held for $8 \mathrm{~min}$ ) and finally increased to $380^{\circ} \mathrm{C}$ at $30^{\circ} \mathrm{C} / \mathrm{min}$ and then held for $3 \mathrm{~min}$. Cholesterol, three cholesterol precursors (desmosterol, lathosterol and lanosterol) and eight OHCs were eluted within $7 \mathrm{~min}$, while six CEs were eluted in the order of the number of carbons in the hydrocarbon chain: cholesteryl laurate (CE 12:0), myristate (CE 14:0), palmitate (CE 16:0), oleate (CE 18:1), linoleate (CE 18:2) and stearate (CE 18:0) (Son et al. 2014).

\section{Hair metabolomics for monitoring potential biomarkers of urological diseases}

Although the acute monitoring for drug efficacy is not applicable with hair analysis, hair steroid analysis still gives us the valuable information to confirm the $5 \alpha$-reductase inhibition after dutasteride administration (Jung et al. 2011). With the same pathological events, the biochemical mechanism of male pattern baldness (MPB) was clearly confirmed with hair steroid analysis (Choi et al. 2001b), and mode of actions of sex steroids in
MPB hair samples was differentiated between Caucasian and Korean (Choi et al. 2013). In addition to the androgen actions, the cortisol metabolic alteration can be monitored as a biochemical marker of chronic stress, which is an excessive symptom that causes cumulative negative impacts on health outcomes (Lee et al. 2015). The detection of cortisol in biological fluids, even saliva, has still been questionable. The increased levels of hair cortisol were observed in childhood obesity, which were also linked to long-term activation of HPA axis (Veldhorst et al. 2014), and the risk of cardiovascular disease (Manenschijn et al. 2013). Recently, our research team was able to successfully establish the analytical method for the profiling of cholesterol precursors and metabolites (e.g., $7 \beta$-hydroxylation of cholesterol).

In the laboratory setting, we have observed that high circulating cholesterol in blood could be associated with high levels of androgens and hair loss in male mice (Fig. 3). Nude mice were grouped ( $n=5 /$ each group) and fed with high-cholesterol diet or normal chow for 2 months. No weight changes or liver function or dysfunction was observed. Levels of cholesterol and androgen were increased in all mice of high-cholesterol group (five out of five mice). Interestingly, three out of five mice in highcholesterol group showed hair loss (Fig. 3).

Although increased androgen levels have been associated with both PC and MPB (Demark-Wahnefried et al. 1997), no studies have shown an association in hair samples. In establishing a proof of concept, our pilot study showed the increased levels of DHEA, testosterone

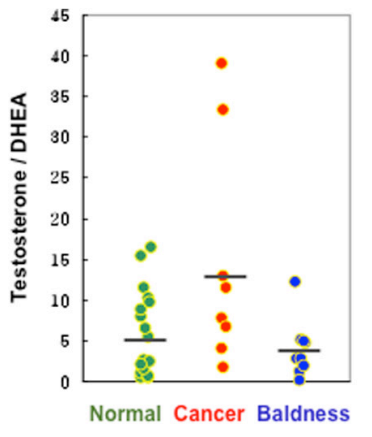

http://erc.endocrinology-journals.org DOI: 10.1530/ERC-16-0285
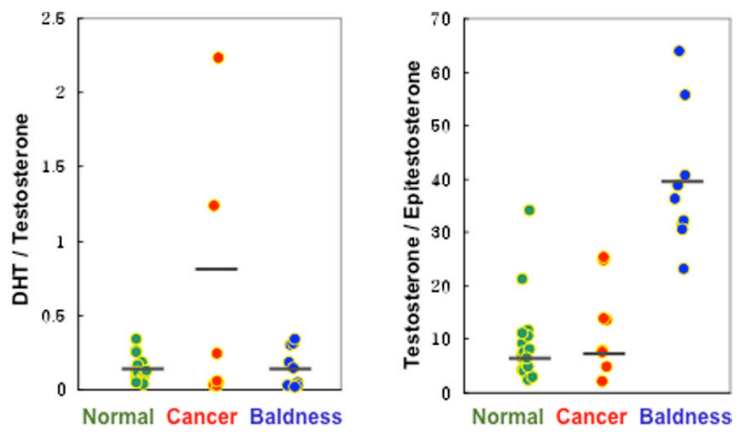

Figure 4

Metabolic ratios of hair androgens in patients with prostate cancer and male pattern baldness compared with healthy control subjects. Line within the value represents the median. 


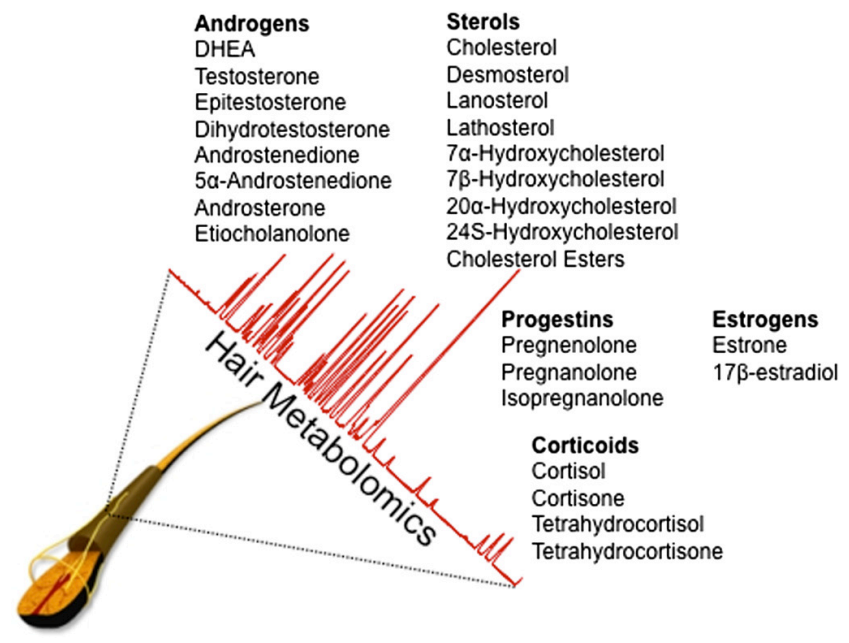

Figure 5

The clinically applicable hair metabolomic approaches to monitor cholesterol and steroid hormone levels in urological diseases.

and DHT in hair samples obtained from both PC and MPB subjects compared with those of age-/sex-matched control subjects. In particular, the metabolic ratios of testosterone:DHEA and DHT:testosterone in PC group tended to increase against the other two groups, whereas a metabolic ration of testosterone:epitestosterone was significantly increased in MPB group (Fig. 4). This is in accordance with our previous findings (Manenschijn et al. 2013). These results suggest that the altered metabolic ratios of androgens combined with the higher levels of androgens might serve as the potential biomarkers for $\mathrm{PC}$ and MPB.

\section{Concluding remarks and perspectives}

PC and $\mathrm{BPH}$ are characterized by alterations of steroidogenic genes, which are important in synthesis of androgens from cholesterol, or genes converting adrenal androgens to DHT or DHT to inactive metabolites. In this short review article, we summarized these cholesterol and sex steroid metabolic pathways during progression of PC and BPH. Given the evidence derived from our and others' laboratories, hair metabolomics could be used for monitoring lipoidal hormones, such as cholesterol and sex steroids as well as corticoids. Both synthesis and metabolism of sex steroids with intracrine or paracrine actions are expressed locally in skin, which serve as a target for various steroid hormones including cholesterol (Slominski 2005). Hair as the adnexal structure of the skin contains the entire biochemical apparatus necessary for the production of steroid hormones either from precursors of systemic origin or, alternatively, through the conversion of steroid precursors. Thus, hair metabolomics could therefore be a promising technique for the retrospective assessment of physiological changes in many clinical events including urological diseases. Figure 5 shows important lipid metabolites that our laboratory has successfully established, with the optimized quantitative analysis methods to measure cholesterol and sex steroid hormones for monitoring, using hair metabolomics.

Declaration of interest

The authors declare that there is no conflict of interest that could be perceived as prejudicing the impartiality of this review.

\section{Funding}

The authors acknowledge the support from the Korea Institute of Science and Technology Institutional Program (Project No. 2E26110 (to M H C)), National Institutes of Health grants (1U01DK103260, 1R01DK100974, U24 DK097154, NIH NCATS UCLA CTSI UL1TR000124 (to J K)), Department of Defense grants (PR140285 (to J K)), Centers for Disease Control and Prevention (1U01DP006079 (to J K)), IMAGINE NO IC Research Grant, the Steven Spielberg Discovery Fund in Prostate Cancer Research Career Development Award, and U.S. - Egypt Science and Technology Development Fund by the National Academies of Sciences, Engineering, and Medicine. J K is the former recipient of Interstitial Cystitis Association Pilot Grant, a Fishbein Family IC Research Grant, New York Academy of Medicine, and Boston Children's Hospital Faculty Development.

\section{Authors' contribution statement}

M H C and J K designed the study, led obtaining funding and overviewed the literature analysis and drafting the manuscript. J Y M performed the analysis of references and assisted in writing the manuscript. All authors read and approved the final manuscript.

\section{Acknowledgements}

The authors would like to thank Mr Taeeun Daniel Park for careful review and editing the manuscript.

\section{Availability of data and materials}

All the data supporting the findings here is contained within the manuscript.

\section{References}

Allott EH \& Hursting SD 2015 Obesity and cancer: mechanistic insights from transdisciplinary studies. Endocrine-Related Cancer 22 R365-R386. (doi:10.1530/ERC-15-0400)

Ahmida HS, Bertucci P, Franzo L, Massoud R, Cortese C, Lala A \& Federici G 2006 Simultaneous determination of plasmatic phytosterols and cholesterol precursors using gas chromatographymass spectrometry (GC-MS) with selective ion monitoring (SIM). Journal of Chromatography B $\mathbf{8 4 2}$ 43-47. (doi:10.1016/j. jchromb.2006.05.024) 
Bielska AA, Schlesinger P, Covey DF \& Ory DS 2012 Oxysterols as non-genomic regulators of cholesterol homeostasis. Trends in Endocrinology and Metabolism 23 99-106. (doi:10.1016/j. tem.2011.12.00)

Bjorkhem I 2002 Do oxysterols control cholesterol homeostasis? Journal of Clinical Investigation 110 725-730. (doi:10.1172/JCI16388)

Bodin K, Andersson U, Rystedt E, Ellis E, Norlin M, Pikuleva I, Eggertsen G, Björkhem I \& Diczfalusy U 2002 Metabolism of 4 betahydroxycholesterol in humans. Journal of Biological Chemistry $\mathbf{2 7 7}$ 31534-31540. (doi:10.1074/jbc.M201712200)

Burkard I, Rentsch KM \& von Eckardstein A 2004 Determination of 24S- and 27-hydroxycholesterol in plasma by high-performance liquid chromatography-mass spectrometry. Journal of Lipid Research 45 776-781. (doi:10.1194/jlr.D300036-JLR200)

Bylda C, Thiele R, Kobold U \& Volmer DA 2014 Recent advances in sample preparation techniques to overcome difficulties encountered during quantitative analysis of small molecules from biofluids using LC-MS/MS. Analyst 139 2265-2276. (doi:10.1039/ c4an00094c)

Chan J, Sauve B, Tokmakejian S, Koren G \& Van Uum S 2014 Measurement of cortisol and testosterone in hair of obese and non-obese human subjects. Experimental and Clinical Endocrinology and Diabetes 122 356-362. (doi:10.1055/s-0034-1374609)

Chen W, Thiboutot D \& Zouboulis CC 2002 Cutaneous androgen metabolism: basic research and clinical perspectives. Journal of Investigative Dermatology 119 992-1007. (doi:10.1046/j.15231747.2002.00613.x)

Cho HJ, Kim JD, Lee WY, Chung BC \& Choi MH 2009 Quantitative metabolic profiling of 21 endogenous corticosteroids in urine by liquid chromatography-triple quadrupole-mass spectrometry. Analytica Chimica Acta 632 101-108. (doi:10.1016/j.aca. 2008.10.059)

Cho SH, Choi MH, Sim WY, Lee WY \& Chung BC 2010 Metabolic alterations of DHEA and cholesterol sulphates in the hair of patients with acne measured by liquid chromatography-mass spectrometry. Experimental Dermatology 19 694-696. (doi:10.1111/j.16000625.2010.01094.x)

Choi MH \& Chung BC 1999 GC-MS determination of steroids related to androgen biosynthesis in human hair with pentafluorophenyldimethylsilyl-trimethylsilyl derivatisation. Analyst 124 1297-300. (doi:10.1039/a903912k)

Choi MH \& Chung BC 2015 Bringing GC-MS profiling of steroids into clinical applications. Mass Spectrometry Reviews 34 219-236. (doi:10.1002/mas.21436)

Choi MH, Kim KR \& Chung BC 2000 Determination of estrone and 17 beta-estradiol in human hair by gas chromatography-mass spectrometry. Analyst 125 711-714. (doi:10.1039/a909107f)

Choi MH, Kim KR, Kim IS, Lho DS \& Chung BC 2001a Increased hair polyamine levels in patients with Alzheimer's disease. Annals of Neurology 50 128. (doi:10.1002/ana.1086)

Choi MH, Yoo YS \& Chung BC $2001 b$ Biochemical roles of testosterone and epitestosterone to 5 alpha-reductase as indicators of male-pattern baldness. Journal of Investigative Dermatology 116 57-61. (doi:10.1046/j.1523-1747.2001.00188.x)

Choi MH, Hahm JR, Jung BH \& Chung BC 2002 Measurement of corticoids in the patients with clinical features indicative of mineralocorticoid excess. Clinica Chimica Acta 320 95-99. (doi:10.1016/S0009-8981(02)00050-5)

Choi MH, Moon JY, Cho SH, Chung BC \& Lee EJ 2011 Metabolic alteration of urinary steroids in pre- and post-menopausal women, and men with papillary thyroid carcinoma. BMC Cancer 11342. (doi:10.1186/1471-2407-11-342)

Choi MH, Kim SJ, Lew BL, Sim WY \& Chung BC 2013 Hair steroid profiling reveals racial differences in male pattern baldness between Korean and Caucasian populations. Journal of Investigative Dermatology 133 822-824. (doi:10.1038/jid.2012.349)
DeBarber AE, Lutjohann D, Merkens L \& Steiner RD 2008 Liquid chromatography-tandem mass spectrometry determination of plasma 24S-hydroxycholesterol with chromatographic separation of 25-hydroxycholesterol. Analytical Biochemistry 381 151-153. (doi:10.1016/j.ab.2008.05.037)

Dehm SM \& Tindall DJ 2007 Androgen receptor structural and functional elements: role and regulation in prostate cancer. Molecular Endocrinology 21 2855-2863. (doi:10.1210/me.2007-0223)

Demark-Wahnefried W, Lesko SM, Conaway MR, Robertson CN, Clark RV, Lobaugh B, Mathias BJ, Strigo TS \& Paulson DF 1997 Serum androgens: associations with prostate cancer risk and hair patterning. Journal of Andrology 18 495-500. (doi:10.1002/j.1939-640.1997.tb01964.x)

Demierre MF, Higgins PD, Gruber SB, Hawk E \& Lippman SM 2005 Statins and cancer prevention. Nature Reviews Cancer 5 930-942. (doi:10.1038/nrc1751)

Fagherazzi G, Fabre A, Boutron-Ruault MC \& Clavel-Chapelon F 2010 Serum cholesterol level, use of a cholesterol-lowering drug, and breast cancer: results from the prospective E3N cohort. European Journal of Cancer Prevention 19 120-125. (doi:10.1097/ CEJ.0b013e3283354918)

Falk RT, Xu X, Keefer L, Veenstra TD \& Ziegler RG 2008 A liquid chromatography-mass spectrometry method for the simultaneous measurement of 15 urinary estrogens and estrogen metabolites: assay reproducibility and interindividual variability. Cancer Epidemiology of Biomarkers and Prevention 17 3411-3418. (doi:10.1158/1055-9965. EPI-08-0355)

Falkenstein E, Tillmann HC, Christ M, Feuring M \& Wehling M 2000 Multiple actions of steroid hormones - a focus on rapid, nongenomic effects. Pharmacological Review 52 513-556.

Farwell WR, Scranton RE, Lawler EV, Lew RA, Brophy MT, Fiore LD \& Gaziano JM 2008 The association between statins and cancer incidence in a veterans population. Journal of National Cancer Institute 100 134-139. (doi:10.1093/jnci/djm286)

Farwell WR, Lourenco C, Holmberg E, Hall RB, D'Avolio L, Lawler EV \& Michael Gaziano J 2011 The association between height and prostate cancer grade in the Early Stage Prostate Cancer Cohort Study. Cancer Causes and Control 22 1453-1459. (doi:10.1007/ s10552-011-9820-x)

Folch J, Lees M \& Sloane Stanley GH 1957 A simple method for the isolation and purification of total lipides from animal tissues. Journal of Biological Chemistry 226 497-509.

Fryar CD, Hirsch R, Eberhardt MS, Yoon SS \& Wright JD 2010 Hypertension, high serum total cholesterol, and diabetes: racial and ethnic prevalence differences in U.S. adults, 1999-2006. NCHS Data Brief 36 1-8.

Gacci M, Corona G, Vignozzi L, Salvi M, Serni S, De Nunzio C, Tubaro A, Oelke M, Carini M \& Maggi M 2015 Metabolic syndrome and benign prostatic enlargement: a systematic review and metaanalysis. BJU International 115 24-31. (doi:10.1111/bju.12728)

Goedeke L \& Fernandez-Hernando C 2012 Regulation of cholesterol homeostasis. Cellular and Molecular Life Sciences 69 915-930. (doi:10.1007/s00018-011-0857-5)

Gray BP, Viljanto M, Bright J, Pearce C \& Maynard S 2013 Investigations into the feasibility of routine ultra high performance liquid chromatography-tandem mass spectrometry analysis of equine hair samples for detecting the misuse of anabolic steroids, anabolic steroid esters and related compounds. Analytica Chimica Acta $\mathbf{7 8 7}$ 163-172. (doi:10.1016/j.aca.2013.05.058)

Griffiths WJ, Wang Y, Alvelius G, Liu S, Bodin K \& Sjovall J 2006 Analysis of oxysterols by electrospray tandem mass spectrometry. Journal of the American Society for Mass Spectrometry 17 341-362. (doi:10.1016/j.jasms.2005.10.012)

Griffiths WJ, Wang Y, Karu K, Samuel E, McDonnell S, Hornshaw M \& Shackleton C 2008 Potential of sterol analysis by liquid chromatography-tandem mass spectrometry for 
the prenatal diagnosis of Smith-Lemli-Opitz syndrome. Clinical Chemistry 54 1317-1324. (doi:10.1373/clinchem.2007. 100644)

Ha YW, Moon JY, Jung HJ, Chung BC \& Choi MH 2009 Evaluation of plasma enzyme activities using gas chromatography-mass spectrometry based steroid signatures. Journal of Chromatography $B$ 877 4125-4132. (doi:10.1016/j.jchromb.2009.11.010)

Honda A, Yamashita K, Hara T, Ikegami T, Miyazaki T, Shirai M, Xu G, Numazawa M \& Matsuzaki Y 2009 Highly sensitive quantification of key regulatory oxysterols in biological samples by LC-ESI-MS/MS. Journal of Lipid Research 50 350-357. (doi:10.1194/jlr.D800040JLR200)

Hsing AW, Stanczyk FZ, Belanger A, Schroeder P, Chang L, Falk RT \& Fears TR 2007 Reproducibility of serum sex steroid assays in men by RIA and mass spectrometry. Cancer Epidemiology, Biomarkers and Prevention 16 1004-1008. (doi:10.1158/1055-9965. EPI-06-0792)

Ito K 2014 Prostate cancer in Asian men. Nature Reviews Urology 11 197-212. (doi:10.1038/nrurol.2014.42)

Jung HJ, Lee WY, Chung BC \& Choi MH 2009 Mass spectrometric profiling of saturated fatty acid esters of steroids separated by high-temperature gas chromatography. Journal of Chromatography $A$ 1216 1463-1468. (doi:10.1016/j.chroma.2008.12.059)

Jung HJ, Lee WY, Yoo YS, Chung BC \& Choi MH 2010 Databasedependent metabolite profiling focused on steroid and fatty acid derivatives using high-temperature gas chromatography-mass spectrometry. Clinica Chimica Acta 411 818-824. (doi:10.1016/ j.cca.2010.02.068)

Jung HJ, Kim SJ, Lee WY, Chung BC \& Choi MH 2011 Gas chromatography/mass spectrometry based hair steroid profiling may reveal pathogenesis in hair follicles of the scalp. Rapid Communications in Mass Spectrometry 25 1184-1192. (doi:10.1002/ rcm.4975)

Karu K, Turton J, Wang Y \& Griffiths WJ 2011 Nano-liquid chromatography-tandem mass spectrometry analysis of oxysterols in brain: monitoring of cholesterol autoxidation. Chemistry and Physics of Lipids 164 411-424. (doi:10.1016/j.chemphyslip. 2011.04.011)

Karuna R, von Eckardstein A \& Rentsch KM 2009 Dopant assistedatmospheric pressure photoionization (DA-APPI) liquid chromatography-mass spectrometry for the quantification of 27-hydroxycholesterol in plasma. Journal of Chromatography B $\mathbf{8 7 7}$ 261-268. (doi:10.1016/j.jchromb.2008.12.033)

Kim JY, Cheong JC, Lee JI \& In MK 2011 Improved gas chromatography-negative ion chemical ionization tandem mass spectrometric method for determination of 11-nor-Delta9tetrahydrocannabinol-9-carboxylic acid in hair using mechanical pulverization and bead-assisted liquid-liquid extraction. Forensic Science International 206 e99-e102. (doi:10.1016/j. forsciint.2011.01.013)

Kraemer FB 2007 Adrenal cholesterol utilization. Molecular and Cellular Endocrinology 265-266 42-45. (doi:10.1016/j.mce.2006.12.001)

Krycer JR \& Brown AJ 2013 Cholesterol accumulation in prostate cancer: a classic observation from a modern perspective. Biochimica et Biophysica Acta 1835 219-229. (doi:10.1016/j.bbcan. 2013.01.002)

Lee DY, Kim E \& Choi MH 2015 Technical and clinical aspects of cortisol as a biochemical marker of chronic stress. BMB Reports $\mathbf{4 8}$ 209-216. (doi:10.5483/BMBRep.2015.48.4.275)

Lembcke J, Ceglarek U, Fiedler GM, Baumann S, Leichtle A \& Thiery J 2005 Rapid quantification of free and esterified phytosterols in human serum using APPI-LC-MS/MS. Journal of Lipid Research $\mathbf{4 6}$ 21-26. (doi:10.1194/jlr.C400004-JLR200)

Manenschijn L, Schaap L, van Schoor NM, van der Pas S, Peeters GM, Lips P, Koper JW \& van Rossum EF 2013 High longterm cortisol levels, measured in scalp hair, are associated with a history of cardiovascular disease. Journal of Clinical Endocrinology and Metabolism 98 2078-2083. (doi:10.1210/jc.2012-3663)

Marcos J \& Pozo OJ 2015 Derivatization of steroids in biological samples for GC-MS and LC-MS analyses. Bioanalysis 7 2515-2636. (doi:10.4155/bio.15.176)

Mass AY, Agalliu I, Laze J \& Lepor H 2012 Preoperative statin therapy is not associated with biochemical recurrence after radical prostatectomy: our experience and meta-analysis. Journal of Urology 188 786-791. (doi:10.1016/j.juro.2012.05.011)

Maxfield FR \& Tabas I 2005 Role of cholesterol and lipid organization in disease. Nature 438 612-621. (doi:10.1038/nature04399)

McDonald JG, Smith DD, Stiles AR \& Russell DW 2012 A comprehensive method for extraction and quantitative analysis of sterols and secosteroids from human plasma. Journal of Lipid Research $\mathbf{5 3}$ 1399-1409. (doi:10.1194/jlr.D022285)

Miller WL 2008 Steroidogenic enzymes. Endocrine Development 13 1-18. (doi:10.1159/000134751)

Miyaguchi H, Kakuta M, Iwata YT, Matsuda H, Tazawa H, Kimura H \& Inoue H 2007 Development of a micropulverized extraction method for rapid toxicological analysis of methamphetamine in hair. Journal of Chromatography A 1163 43-48. (doi:10.1016/j. chroma.2007.06.017)

Mondul AM, Weinstein SJ, Virtamo J \& Albanes D 2011 Serum total and HDL cholesterol and risk of prostate cancer. Cancer Causes and Control 22 1545-1552. (doi:10.1007/s10552-011-9831-7)

Moon JY, Jung HJ, Moon MH, Chung BC \& Choi MH 2009 Heat-map visualization of gas chromatography-mass spectrometry based quantitative signatures on steroid metabolism. Journal of the American Society for Mass Spectrometry 20 1626-1637. (doi:10.1016/ j.jasms.2009.04.020)

Moon JY, Ha YW, Moon MH, Chung BC \& Choi MH 2010 Systematic error in gas chromatography-mass spectrometry-based quantification of hydrolyzed urinary steroids. Cancer Epidemiology, Biomarkers and Prevention 19 388-397. (doi:10.1158/1055-9965. EPI-09-0581)

Moon JY, Kang SM, Moon MH, Hong J, Kim KT, Jeong DH, Kim YN, Chung BC \& Choi MH 2011a Extractive ethoxycarbonylation in high-temperature gas chromatography-mass spectrometry based analysis of serum estrogens. Journal of Chromatography B $\mathbf{8 7 9}$ 3742-3748. (doi:10.1016/j.jchromb.2011.10.024)

Moon JY, Kim KJ, Moon MH, Chung BC \& Choi MH $2011 b$ A novel GC-MS method in urinary estrogen analysis from postmenopausal women with osteoporosis. Journal of Lipid Research 52 1595-1603. (doi:10.1194/jlr.D016113)

Moon JY, Moon MH, Kim KT, Jeong DH, Kim YN, Chung BC \& Choi MH 2014 Cytochrome P450-mediated metabolic alterations in preeclampsia evaluated by quantitative steroid signatures. Journal of Steroid Biochemistry and Molecular Biology 139 182-191. (doi:10.1016/j.jsbmb.2013.02.014)

Mostaghel EA, Solomon KR, Pelton K, Freeman MR \& Montgomery RB 2012 Impact of circulating cholesterol levels on growth and intratumoral androgen concentration of prostate tumors. PLOS ONE 7 e30062. (doi:10.1371/journal.pone.0030062)

Musshoff F, Kirschbaum KM, Graumann K, Herzfeld C, Sachs H \& Madea B 2012 Evaluation of two immunoassay procedures for drug testing in hair samples. Forensic Science International 215 60-63. (doi:10.1016/j.forsciint.2011.03.030)

Nielsen SF, Nordestgaard BG \& Bojesen SE 2012 Statin use and reduced cancer-related mortality. New England Journal of Medicine $\mathbf{3 6 7}$ 1792-1802. (doi:10.1056/NEJMoa1201735)

Ohnemus U, Uenalan M, Inzunza J, Gustafsson JA \& Paus R 2006 The hair follicle as an estrogen target and source. Endocrine Reviews 27 677-706. (doi:10.1210/er.2006-0020)

Park HS, Schoenfeld JD, Mailhot RB, Shive M, Hartman RI, Ogembo R \& Mucci LA 2013 Statins and prostate cancer recurrence following radical prostatectomy or radiotherapy: a systematic review and
() 2016 The authors Printed in Great Britain
Published by Bioscientifica Ltd 
meta-analysis. Annals of Oncology 24 1427-1434. (doi:10.1093/ annonc/mdt077)

Payne AH \& Hales DB 2004 Overview of steroidogenic enzymes in the pathway from cholesterol to active steroid hormones. Endocrine Reviews 25 947-970. (doi:10.1210/er.2003-0030)

Pelton K, Freeman MR \& Solomon KR 2012 Cholesterol and prostate cancer. Current Opinion in Pharmacology 12 751-759. (doi:10.1016/ j.coph.2012.07.006)

Penning TM, Lee SH, Jin Y, Gutierrez A \& Blair IA 2010 Liquid chromatography-mass spectrometry (LC-MS) of steroid hormone metabolites and its applications. Journal of Steroid Biochemistry and Molecular Biology 121 546-555. (doi:10.1016/j.jsbmb. 2010.01.005)

Pereg D, Chan J, Russell E, Berlin T, Mosseri M, Seabrook JA, Koren G \& Van Uum S 2013 Cortisol and testosterone in hair as biological markers of systolic heart failure. Psychoneuroendocrinology $\mathbf{3 8}$ 2875-2882. (doi:10.1016/j.psyneuen.2013.07.015)

Pichini S, De Luca R, Pellegrini M, Marchei E, Rotolo MC, Spoletini R, D'Aloja P, Paciflci R, Mortali C \& Scaravelli G 2012 Hair and urine testing to assess drugs of abuse consumption in couples undergoing assisted reproductive technology (ART). Forensic Science International 218 57-61. (doi:10.1016/j.forsciint.2011.10.011)

Pikuleva IA 2006 Cholesterol-metabolizing cytochromes P450. Drug Metabolism and Disposition 34 513-520. (doi:10.1124/dmd.105. 008789)

Platz EA, Clinton SK \& Giovannucci E 2008 Association between plasma cholesterol and prostate cancer in the PSA era. International Journal of Cancer 123 1693-1698. (doi:10.1002/ijc.23715)

Platz EA, Till C, Goodman PJ, Parnes HL, Figg WD, Albanes D, Neuhouser ML, Klein EA, Thompson IM Jr \& Kristal AR 2009 Men with low serum cholesterol have a lower risk of high-grade prostate cancer in the placebo arm of the prostate cancer prevention trial. Cancer Epidemiology, Biomarkers and Prevention 18 2807-2813. (doi:10.1158/1055-9965.EPI-09-0472)

Pucci V, Di Palma S, Alfieri A, Bonelli F \& Monteagudo E 2009 A novel strategy for reducing phospholipids-based matrix effect in LC-ESI-MS bioanalysis by means of HybridSPE. Journal of Pharmaceutical and Biomedical Analysis 50 867-871. (doi:10.1016/ j.jpba.2009.05.037)

Ridker PM \& Cook NR 2013 Statins: new American guidelines for prevention of cardiovascular disease. Lancet 382 1762-1765. (doi:10.1016/S0140-6736(13)62388-0)

Ryu HK, Jung BH, Kim KM, Yoo EA, Woo JT \& Chung BC 2006 Determination of cholesterol in human hair using gas chromatography-mass spectrometry. Biomedical Chromatography 20 999-1003. (doi:10.1002/bmc.615)

Scosyrev E, Tobis S, Donsky H, Wu G, Joseph J, Rashid H \& Messing E 2013 Statin use and the risk of biochemical recurrence of prostate cancer after definitive local therapy: a meta-analysis of eight cohort studies. BJU International 111 E71-E77. (doi:10.1111/j.1464410X.2012.11527.x)

Seo HS \& Choi MH 2015 Cholesterol homeostasis in cardiovascular disease and recent advances in measuring cholesterol signatures. Journal of Steroid Biochemistry and Molecular Biology 153 72-79. (doi:10.1016/j.jsbmb.2015.04.014)

Shafique K, McLoone P, Qureshi K, Leung H, Hart C \& Morrison DS 2012 Cholesterol and the risk of grade-specific prostate cancer incidence: evidence from two large prospective cohort studies with up to 37 years' follow up. BMC Cancer 12 25. (doi:10.1186/14712407-12-25)

Shareef A, Angove MJ \& Wells JD 2006 Optimization of silylation using N-methyl-N-(trimethylsilyl)-trifluoroacetamide, $\mathrm{N}, \mathrm{O}$-bis-(trimethylsilyl)-trifluoroacetamide and N-(tertbutyldimethylsilyl)-N-methyltrifluoroacetamide for the determination of the estrogens estrone and 17alphaethinylestradiol by gas chromatography-mass spectrometry.
Journal of Chromatography A 1108 121-128. (doi:10.1016/ j.chroma.2005.12.098)

Simon A 2014 Cholesterol metabolism and immunity. New England Journal of Medicine 371 1933-1935. (doi:10.1056/NEJMcibr 1412016)

Singh EJ \& Gershbein LL 1967 Phospholipids of human hair lipids. Journal of Chromatography 31 20-27. (doi:10.1016/S00219673(01)86020-9)

Slominski A 2005 Neuroendocrine system of the skin. Dermatology 211 199-208. (doi:10.1159/000087012)

Son HH, Moon JY, Seo HS, Kim HH, Chung BC \& Choi MH 2014 High-temperature GC-MS-based serum cholesterol signatures may reveal sex differences in vasospastic angina. Journal of Lipid Research 55 155-162. (doi:10.1194/jlr.D040790)

Son HH, Kim SH, Moon JY, Chung BC, Park MJ \& Choi MH 2015 Serum sterol profiling reveals increased cholesterol biosynthesis in childhood obesity. Journal of Steroid Biochemistry and Molecular Biology 149 138-145. (doi:10.1016/j.jsbmb.2015.02.012)

Son HH, Lee DY, Seo HS, Jeong J, Moon JY, Lee JE, Chung BC, Kim E \& Choi MH 2016 Hair sterol signatures coupled to multivariate data analysis reveal an increased 7beta-hydroxycholesterol production in cognitive impairment. Journal of Steroid Biochemistry and Molecular Biology 155 9-17. (doi:10.1016/j.jsbmb. 2015.09.024)

Spiehler V 2000 Hair analysis by immunological methods from the beginning to 2000. Forensic Science International 107 249-259. (doi:10.1016/S0379-0738(99)00168-1)

Sulek K, Han TL, Villas-Boas SG, Wishart DS, Soh SE, Kwek K, Gluckman PD, Chong YS, Kenny LC \& Baker PN 2014 Hair metabolomics: identification of fetal compromise provides proof of concept for biomarker discovery. Theranostics 4 953-959. (doi:10.7150/thno.9265)

Thomson S, Koren G, Van Steen V, Rieder M \& Van Uum SH 2009 Testosterone concentrations in hair of hypogonadal men with and without testosterone replacement therapy. Therapeutic Drug Monitoring 31 779-782. (doi:10.1097/FTD. Ob013e3181c004f1)

Tworoger SS \& Hankinson SE 2006 Collection, processing, and storage of biological samples in epidemiologic studies: sex hormones, carotenoids, inflammatory markers, and proteomics as examples. Cancer Epidemiology, Biomarkers and Prevention 15 1578-1581. (doi:10.1158/1055-9965.EPI-06-0629)

Veldhorst MA, Noppe G, Jongejan MH, Kok CB, Mekic S, Koper JW, van Rossum EF \& van den Akker EL 2014 Increased scalp hair cortisol concentrations in obese children. Journal of Clinical Endocrinology and Metabolism 99 285-290. (doi:10.1210/ jc.2013-2924)

Villain M, Cirimele V \& Kintz P 2004 Hair analysis in toxicology. Clinical Chemistry and Laboratory Medicine 42 1265-1272. (doi:10.1515/CCLM.2004.247)

Wang Q, Rangiah K, Mesaros C, Snyder NW, Vachani A, Song H \& Blair IA 2015 Ultrasensitive quantification of serum estrogens in postmenopausal women and older men by liquid chromatographytandem mass spectrometry. Steroids 96 140-152. (doi:10.1016/ j.steroids.2015.01.014)

Wennig R 2000 Potential problems with the interpretation of hair analysis results. Forensic Science International 107 5-12. (doi:10.1016/ S0379-0738(99)00146-2)

Wood L, Ducroq DH, Fraser HL, Gillingwater S, Evans C, Pickett AJ, Rees DW, John R \& Turkes A 2008 Measurement of urinary free cortisol by tandem mass spectrometry and comparison with results obtained by gas chromatography-mass spectrometry and two commercial immunoassays. Annals of Clinical Biochemistry 45 380-388. (doi:10.1258/acb.2007.007119)

Wudy SA, Hartmann M \& Homoki J 2000 Hormonal diagnosis of 21-hydroxylase deficiency in plasma and urine of neonates using

Published by Bioscientifica Ltd. 
benchtop gas chromatography-mass spectrometry. Journal of Endocrinology 165 679-683. (doi:10.1677/joe.0.1650679)

Xu X, Keefer LK, Ziegler RG \& Veenstra TD 2007 A liquid chromatography-mass spectrometry method for the quantitative analysis of urinary endogenous estrogen metabolites. Nature Protocol 2 1350-1355. (doi:10.1038/nprot.2007.176)

Yamashita K, Okuyama M, Watanabe Y, Honma S, Kobayashi S \& Numazawa M 2007 Highly sensitive determination of estrone and estradiol in human serum by liquid chromatography-electrospray ionization tandem mass spectrometry. Steroids 72 819-827. (doi:10.1016/j.steroids.2007.07.003)

YuPeng L, YuXue Z, PengFei L, Cheng C, YaShuang Z, DaPeng L \& Chen D 2015 Cholesterol levels in blood and the risk of prostate cancer: a metaanalysis of 14 prospective studies. Cancer Epidemiology, Biomarkers and Prevention 24 1086-1093. (doi:10.1158/1055-9965.EPI-14-1329)

Zhuang L, Lin J, Lu ML, Solomon KR \& Freeman MR 2002 Cholesterolrich lipid rafts mediate akt-regulated survival in prostate cancer cells. Cancer Research 62 2227-2231.

Received in final form 29 July 2016

Accepted 4 August 2016 